\title{
Exploring the Model of Applying the Theory of Conceptual Metaphor to English Intensive Reading Teaching
}

\author{
Rui Li \\ School of Foreign Languages \\ Henan University of Chinese Medicine \\ Zhengzhou, China
}

\begin{abstract}
Based on the analysis of the relationships between conceptual metaphor and culture, conceptual metaphor and text coherence, conceptual metaphor and language elements, conceptual metaphor and productive metaphorical competence, this paper explores the application of the Theory of Conceptual Metaphor to English intensive reading classes, hoping that it can introduce a new perspective to college English teaching.
\end{abstract}

Keywords-the Theory of Conceptual Metaphor; English intensive reading teaching; teaching mode

\section{INTRODUCTION}

Around 1980s, Lakoff and Johnson published a book entitled Metaphors We Live By, which has turned the study of metaphor into a complete cognitive direction. In the book, Lakoff and Johnson claim that "Our ordinary conceptual system, in terms of which we both think and act, is fundamentally metaphorical in nature." (Lakoff and Johnson 1980:3). The Theory of Conceptual Metaphor is aimed at exploring metaphorical phenomenon from cognitive perspective, and it draws the conclusion that conceptual metaphor is a kind of device rooted deep in our cognitive system underlying the surface metaphorical expressions. The nature of conceptual metaphor is the cross-domain mapping from the target domain to the source domain in the conceptual system with its fundamental base being the experience and the direct base being the image schema. The nature of the Theory of Conceptual Metaphor determines that it can be very helpful for EFL teaching, and this paper aims to explore a teaching model concerning how to apply the Theory of Conceptual Metaphor to English intensive reading teaching.

\section{THE THEORY OF CONCEPTUAL METAPHOR AND ENGLISH TEACHING}

According to College English Curriculum Requirements (2007) issued by Chinese ministry of education, the teaching objective of college English curriculum is to cultivate the students' comprehensive English competence, and to enable them to communicate effectively. Meanwhile, it aims at boosting their integrative cultural quality so as to adapt them to the needs of international communication. However, the traditional English intensive reading teaching in China mainly focuses on the lexical and grammatical studies, which has caused many problems, just like what Danesi has said:

....as they enter the twenty-first century, teachers may know a lot more about the nature of linguistic and communicative competence, and about learning theories and learner needs... but paradoxically they still face the same annoying dilemma... why is it that after studying language for carrying periods of time, students still seem to lack the ability to speak with the same kind of 'naturalness' that is instantly detectable in native-speaker text? (Danesi 2000: 13)

From the above, the application of the Theory of Conceptual Metaphor to English intensive reading is a necessity.

\section{A. The Theory of Conceptual Metaphor and Culture}

Firstly, culture shapes and restraints the conceptual metaphor, that is, conceptual metaphor has a very strong cultural tag and it is influenced by culture. Secondly, it is conceptual metaphor systems that constitute the culture. The previous conceptual metaphor based on cultural experience will later serve as the basis for another new conceptual metaphor. This process going on, the conceptual metaphor systems were set up to constitute the culture. Thirdly, conceptual metaphor is the carrier of culture.

In English teaching, we can apply the conceptual metaphor to raising the students' cultural consciousness.

\section{B. Conceptual Metaphor and Text Coherence}

On one hand, due to the fact that conceptual mappings are based on image schema or knowledge, and they can be motivated and extracted from our cognitive system simultaneously without efforts, the writer can employ them easily as a powerful tool to make the text coherent. On the other hand, since conceptual metaphor system and the metaphorical mappings are systematic and coherent in nature and they govern a system of related metaphorical expressions. In this sense, conceptual metaphor is a necessary device to construct the text coherence at the conceptual level. The text is coherent at both the conceptual 
level by conceptual metaphor system and the surface level through specific metaphorical metaphors.

In English teaching, we may regard the conceptual metaphor as a means of text coherence to reveal the main idea of the text.

\section{Conceptual Metaphor and Linguistic Elements}

Since the conceptual metaphor is the deep cognitive mechanism of human thought, it must have a deep influence on the linguistic elements at all levels, such as lexicons, phrases, lexical collocations, sentential expressions.

In English teaching, for one thing, the explanation of conceptual metaphor can help the students deepen and broaden their command of the linguistic element, and diversify their linguistic element output. For another, conceptual metaphorical thinking will make the learning of linguistic element more fruitful and more interesting.

\section{Conceptual Metaphor and Productive Metaphorical Competence}

Conceptual metaphor is the fundamental cognitive mechanism deriving from human's interaction with the environment, and it is a very needy tool in human communication. In language production, we need to rely on conceptual metaphor in our deep mind to construct linguistic expressions and to convey our ideas. In this sense, conceptual metaphor built up in one's cognitive system will govern one's metaphorical output.

In English teaching, to cultivate the productive conceptual metaphorical competence in real intensive English reading teaching, firstly, the teacher should cultivate cognitive view of metaphor. Secondly, the teacher must see to it that the students grasp the deep cultural, social reasons under the conceptual metaphor. Thirdly, the students should be instructed the coherent and cohesive way to achieve textual coherence. Fourthly, the teacher should lead the students to build a semantic field underlying the same conceptual metaphor, and encourage the students to use the diverse expressions in the semantic field. Lastly, the students' productive practice and the teacher's feedback are very important in the cultivation of productive metaphorical competence.

\section{A TEACHING MODEL BASED ON THE APPLICATION OF THE THEORY OF CONCEPTUAL METAPHOR}

Based on the exploration of the functions of the Theory of Conceptual Metaphor to English intensive reading teaching in the last chapter, we can sum up the following teaching model:

Firstly, in the lead-in part of a new text, the teacher does some warming-up activities to introduce the culturally embedded topic-related conceptual metaphors. To be specific, in the lead-in part, the teacher can conduct some brainstorming activities to use the topic-related concept as the center for the students to associate everything they know about it, and then ask the students to present them in terms of conceptual metaphors. As we know, the students' knowledge is based on their own experience in Chinese cultural environment, which might bear some cultural difference to English conceptualization. So next the teacher should list the metaphorical expressions concerning how the topic-related concept is perceived in English culture to arouse the students' cultural consciousness. Then the teacher inspires the students to discover the conceptual metaphor underlying these metaphorical expressions and provides the students with necessary cultural knowledge about the topic-related concept. Next, based on the conceptual metaphor and cultural knowledge of the topic-related concept, the teacher asks the students to make predictions about the text.

By doing this, on one hand, the students are awarded the necessary explicit cultural knowledge for them to perceive the main topic of the text, and they can make reasonable predictions about the text. On the other hand, the teacher can successfully arouse the students' cultural consciousness of the text topic.

Secondly, in text understanding, the teacher can adopt the "bottom-up-bottom" method. At the beginning, the teacher highlights the metaphorical expressions throughout the text as cohesive ties for the students to generate the main underlying theme-related conceptual metaphor which accounts for the coherence of the text. After the generalization of the conceptual metaphor, the teacher should give a detailed explanation about the motivation of the theme-related conceptual metaphor to strengthen the students' understanding of the text's main idea. Next the teacher leads the students to go back to all the metaphorical expressions in the text and inspires the students to have a deeper understanding of text and see how the main idea is coherently conveyed through these metaphorical expressions.

In this way, through the first "bottom-up" process, the students can grasp the main idea of the text, and through the latter "up-bottom" process, the students can deepen their understanding of the text through analyzing the vivid metaphorical expressions and have a clear idea of how the text is coherent at the cognitive level.

Thirdly, the teacher's attention focuses on various linguistic forms at different levels, such as lexicons, phrases, lexical collocations, sentential expressions. To be more specific, the linguistic elements should be approached in the following way: In the beginning, through the exploration of deep cognitive mechanism underlying the linguistic elements, the teacher makes sure the students can understand and use the linguistic elements from a deeper cognitive perspective. Then, if necessary, ask the students to translate these linguistic elements into Chinese to see whether there is a corresponding conceptual mapping in Chinese. By doing this, the students will be more conscious of the different thinking mode between Chinese and English. Next, as we have discussed above, due to the systemacity nature of conceptual metaphor, it can provide a platform to build a semantic network. The teacher could help the students to associate more linguistic elements under the same conceptual metaphor to build up a semantic network. Then with the semantic network forming in the students' mind, the teacher 
encourages the students to use these expressions in their own output through practicing.

By exploring the deep cognitive mechanism underlying these various linguistic elements, the teacher can enhance the students' linguistic, communicative, metaphorical competence in combination with their cultural consciousness.

Fourthly, after learning the text, the teacher gives a topic -related composition task for the students to practice their productive metaphorical ability, since the students can relate more by exposure to so many linguistic expressions in the text. Meanwhile, the teacher asks the students to make their language natural and diverse, coherent and cohesive both at cognitive level and the surface level. At last, the teacher should give feedback to the students' output to enhance their productive metaphorical competence. The teacher can use conceptual metaphor to explain to the students why the expression in the output is inappropriate.

We can use the following diagram to structure this teaching model:

\section{Lead-in:}

topic-related culturally embedded conceptual metaphors introduced as background information

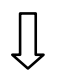

\section{Text Understanding:}

bottom: specific metaphorical expressions used as cohesive ties of the text listed for exploring the deep coherent cognitive mechanism

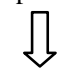

up: theme--related conceptual metaphor summarized for understanding the general idea of the text

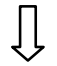

bottom: specific metaphorical expressions analyzed for exploring a deeper understanding of the text

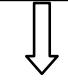

Linguistic element study:

various linguistic elements approached from cognitive perspective to enhance students' linguistic, communicative, metaphorical competence and cultural consciousness

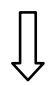

out put practice:

text-related productive task given to enhance productive metaphorical competence

What's more, in order to make the application of the Theory of Conceptual Metaphor to English intensive reading more effective, the following are the general principles we must abide by: Firstly, the teacher's solid and systematic knowledge of the whole set of the Theory of Conceptual Metaphor is a necessity. In real teaching setting, the teacher should make use of their conceptual metaphor knowledge to do as follows: 1 . the teacher must be very conscious of linguistic expressions based on conceptual metaphor to arouse the students' metaphorical awareness; 2. the teacher must analyze the teaching material keenly and deeply. Usually, due to the limited knowledge and experience of the students, they can only undertake the superficial meaning, and sometimes, they just take the metaphorical expressions for granted, considering it as a fixed rule of language. The result is that the students only understand the literal meaning of the linguistic expressions without knowing its cognitive source, and they have to memorize these expressions mechanically. Step by step, they will find studying boring. So the teacher must lead the students to explore the underlying cognitive source of the metaphorical expressions by using their cultural and experiential knowledge in the target language. Secondly, the teacher must integrate the Theory of Conceptual Metaphor with daily experience, and base their teaching on the students' thinking and cognitive characteristics. Thirdly, the teacher should play their roles as a guide, and stimulate the students to display their initiative fully. Since the students' conceptual metaphorical competence must be acquired by themselves under proper instruction by the teacher, the teacher's role is more of a guide than a knowledge giver. On the other hand, since some conceptual metaphors are culturally specific, the students might not have enough knowledge or cultural background to understand them, here the teacher should serve as the guide to steer them towards the target cultural knowledge. Fourthly, the teacher should provide the students with more opportunities for teacher-student interaction. On one hand, the metaphorical linguistic expressions in the interaction between the teacher and the students can stimulate the students to think more, and provide them with more direct input. On the other hand, through more interaction with the students, the teacher can give feedbacks to the students' unnatural metaphorical expressions, which in turn will improve the students' conceptual metaphorical competence in the target language.

Fifthly, the teacher should be conscious of the cultural factors underlying the linguistic metaphorical expressions to arouse the students' cultural consciousness. Sixthly, the teacher should follow a step-by-step procedure. For lacking of cultural environment of the target language, the students can't acquire the typical metaphorical thinking pattern at one sitting. So in practice, following the procedure "Presentation $\rightarrow$ Practice $\rightarrow$ Production" described by Skehan (Skehan, as cited in Wang Baojian and Dou Qin 2011), the teacher can firstly present the whole set of the Theory of Conceptual Metaphor to cultivate cognitive view of metaphor. Then through exposing them to abundant metaphorical expressions and practice, the teacher inspires the students to produce more metaphorical output.

Lastly, the teacher should distinguish conceptual metaphor from specific linguistic metaphor.

\section{CONCLUSION}

Based on the exploration of the application of the Theory of Conceptual Metaphor to English intensive reading teaching, the writer draws the following teaching model: (1). In lead-in part, the teacher introduces the culturally embedded topic-related conceptual metaphors which can serve as background information. (2). In text understanding 
part, the teacher can adopt the "bottom-up-bottom" method. At the beginning, through studying the metaphorical expressions serving as the surface cohesive ties, the teacher leads the students to generate the theme-related conceptual metaphor which governs the consistency of the whole text to understand the general idea of the text. Next the teacher leads the students to go back to study all the metaphorical expressions in the text to have a deeper understanding of text and see how the main idea is coherently conveyed through these metaphorical expressions; (3). In the linguistic element learning part, at the beginning, through the exploration of deep cognitive mechanism underlying the linguistic elements in the text, the teacher makes sure the students can understand and use the linguistic elements from a deeper cognitive perspective. Next, the teacher could help the students to associate more linguistic elements under the same conceptual metaphor to build up a semantic network, and encourage the students to use these expressions in their own output through practicing. (4). In the homework part, the teacher gives a topic-related productive task for the students to practice their productive metaphorical ability.

All in all, the application of the Theory of Conceptual Metaphor to English intensive teaching reading is effective. It involves initiative, imagination, creativity on the students' part, which may in turn lead to the active classroom atmosphere and more interaction between the teacher and the students.

\section{REFERENCES}

[1] Aznma M. (2005) Metaphorical competence in an EFT context the mental lexicon and metaphorical competence of Japanese EFL students. Tokyo: Toshindo Publishing.

[2] Johnson, Mark. (1987) The Body in the Mind. Chicago: The University of Chicago Press.

[3] Kövecses, Zoltan. (2002) Metaphor. New York: Oxford University Press.

[4] Lakoff, G \& Johnson, M. (1980) Metaphors We Live By. Chicago: University of Chicago Press.

[5] Ning Yu. (1998) The Contemporary Theory of Metaphor: A Perspective from Chinese. Philadelphia: John Benjamins Publishing Cooperation. 